\title{
Behavioral and Psychosocial Factors of Quality of Life Among Adult People Living With HIV on Highly Active Antiretroviral Therapy, in Public Hospitals of South West Ethiopia, 2018: a Case Control Study
}

Abreha Addis Gesese ( $\square$ abrhaddis09@gmail.com )

Gambella Teachers Education and Health Science College

Yitages Getachew Desta

Endale zenebe Behire

\section{Research}

Keywords: HIV/AIDS, ART, Quality of life, People living with HIV/AIDS

Posted Date: August 20th, 2020

DOI: https://doi.org/10.21203/rs.3.rs-58729/v1

License: (1) (i) This work is licensed under a Creative Commons Attribution 4.0 International License.

Read Full License 


\section{Abstract}

Background: Despite of the availability of Highly Active Antiretroviral Therapy, people living with HIV/AIDS suffer from socioeconomic, behavioral and psychosocial related factors affecting their quality of life. Previous studies assessed the magnitude of quality of life but the present one will identify behavioral and psychosocial factors associated with poor quality of live among adult PLWHIV on Antiretroviral therapy in the study setting.

Objective: To identify behavioral and psychosocial determinants of Quality of life among Adult PLWHIV on HARRT, in Public Hospitals of Jimma Zone, South West, Ethiopia 2018.

Method: Institution based unmatched case control study was employed. Simple random sampling technique was used to select cases and controls using screening criteria. Interviewer administered data collection method was used. Data were entered into Epi-Data and analyzed using SPSS version 20. Bivariate and multivariate logistic regressions were performed. The study was conducted from March 10April 10- 2018.

Results: A total of $75(25 \%)$ cases and $225(75 \%)$ of controls included in the study. Finally, the odds of poor quality of life among underweight $\left(\mathrm{BMI} \mathrm{kg} / \mathrm{m}^{2}\right) 2.7$ times [AOR $2.795 \% \mathrm{Cl}(1.0,7.1)$ ] more likely than normal /obese respondents, khat chewing 1-4 times/weak/month about 4.5 times [AOR $4.595 \% \mathrm{Cl}(1.85$, 10.9)] and at daily intervals 4.7 times more [AOR $4.795 \% \mathrm{Cl}(1.18,18.8)$ ] likely than who never chew respectively. Being dissatisfied from support AOR $9.895 \% \mathrm{Cl}(1.9,50)$, Stigmatized patients 8 times more likely than non-stigmatized AOR $8.095 \% \mathrm{Cl}(3.6,18.1)$. Moreover, the odds of poor quality of life among severely depressed patients were 4 times AOR $4.095 \% \mathrm{Cl}(1.67,9.83)$ more likely than mild depressed patients.

Conclusion: Being underweight (BMI kg/ ${ }^{2}$ ), khat chewing 1-4 times/weak/month, khat chewing at daily interval, being dissatisfied from support, stigma and depression were independently associated. This may inform possible interventions to reduce comorbidities and disease exacerbation by improving on dietary and nutritional programs and support, reducing behavioral factors, improving social support, reducing stigma and depression by appropriate counseling and strengthening currently existing Information Education Communication to help develop life skills.

\section{Background}

HIV/AIDS is fatal illness that leads to life threatening opportunistic infections, neurological disorder and unusual malignancies which is a public health concern that has progress from mysterious illness to global pandemic $[1,2]$. Sub Saharan Africa region constitutes about greater than half of people living with HIV/AIDS. Ethiopia is among Sub Saharan African with high burdened areas of disease prevalence with $1.1 \%$ with higher distribution in urban and peri-urban areas $[3,4]$. The introduction of highly active antiretroviral therapy (HAART) has become the cornerstone of clinical intervention available to prevent transmission and slow progression of HIV infection in individuals living with HIV/AIDS [5, 6]. It also helps 
living longer and manages properly with diagnosis and treatment provision before HIV is transformed into a chronic illness. It also helped to reduce HIV-related morbidity and mortality, provide maximal and durable suppression of viral load (VL) restore and/or preserve immune function $[7,8,9]$. About $43 \%$ annual number of people dying from AIDS-related causes has been declined due to access to HAART reaching to $54 \%$ among adults of age 15 years and above since 2003 which also improved quality of life $[2,10]$.

Quality of life is therefore, an important outcome measure used in a wide variety of medical research to ascertain aspects of well-being in settings of health and disease. It can be useful for understanding the life experience of PLWHIV which will become more important to evaluate their status and to provide necessary health and social services [10]. It is defined different by different organizations. Communicable Disease Control (CDC) defined Quality of life (QOL) as an overall sense of well-being, including aspects of happiness and satisfaction with life as a whole. It is broad and subjective rather than specific and objective [11]. But commonly used measures in clinical practice include items that clinicians consider relevant to PLWHIV is the use of objective measures which includes severity of symptoms and level of functioning[12]. They also provide a basis for sharing clinical decision making between patients and clinicians, identifying patients' priorities for treatment, and facilitating the setting of realistic treatment goals [13]. Whereas WHO defined quality of life as individuals' perceptions of their position in life in the context of the culture and value systems in which they live and in relation to their goals, expectations, standards and concerns. It refers to a subjective evaluation which focuses upon respondents' "perceived" quality of life[14].

Despite different strategies provoked and tremendous efforts done to halt the spread and consequences of HIV/AIDS both at the global as well as national level, PLWHIV continued to suffer. PLWHIV in a broad ranging concept can be affected in a complex way by the person's physical health, psychological state, level of independence, social relationships, personal beliefs and their relationship to salient features of their environment [14]. Quality of Life(QOL) increased on ART [15]. World Health Organization report of 2015, persons infected and affected with HIV and livelihoods hazards are often subjected to social stigma and discrimination in the workplace and in some cases forced to leave or terminated from employment especially in resource poor settings. Low- and Middle-Income Countries revealed that social support is associated with improvement in access and adherence to ART, medication uptake, retention in care, physical functioning, CD4 cell progression, virologic suppression, body weight of PLWHA, and mortality with improvements in psychosocial functioning $[2,6,10,16]$.

Studies show that HIV/AIDS continues to affect individual's physical, mental, social and financially with a great impact on society both as an illness \& as a source of discrimination and stigma $[2,14]$. It has also been associated in a complex way with impoverished housing conditions and hindering access of PLHIV and affected communities to work and treatment The challenges of slums in urban areas like basic services, inadequate water, sanitation, overcrowding and others are worsened by the impact of HIV/AIDS [17-18]. According to the report from UNAIDS in Ethiopia People who report they would not buy vegetables from a Shop-keeper living with HIV is (59.9\%)[19]. The study from Bahir-dar felegehiwot revealed more 
than half were with low QOL and study from Mekele showed significant gender differences with lower HRQOL in females almost in all domains [20,21].

A number of studies have been carried out on quality of life of people living with HIV/AIDS[22-29]. Good nutrition is essential for achieving and preserving health while helping the body to protect itself from infections. It can, therefore, improve the quality of life of PLHIV and help them live longer [30]. Most of them are cross sectional in nature with some other studies. None of these have assessed the role of behavioral, psychosocial factors on quality of life among adult PLWHIV [31-34]. Knowing those factors enable to understand for appropriate evaluation and monitor patient outcomes. Therefore, this study was aimed to identify behavioral and psychosocial factors affecting quality of life among PLWHIV on HAART in the study settings.

\section{Methods}

Study area and period-the study was conducted in Jimma Zone public hospitals, Southwest Ethiopia. Jimma zone is located $357 \mathrm{Kms}$ Southwest of Addis Ababa. Jimma zone is found in a region that accounted for the highest number of HIV infected people from Ethiopia. It is found near Gambella region, a region that accounted for the highest prevalence rate of HIV from Ethiopia[3]. The study was taken place in four public hospitals called Jimma University Medical Center (JUMC), Shenen Gibe hospital (SGH), Agaro hospital (AH) and Limu Genet hospital (LGH). These were selected due to the provision of ART services for a long period of time, have many patients on ART and their electronic medical records. These health institutions serve a catchment area of 3 million people with about 11,500 PLWHA were on follow up HIV chronic care during the study. The study was done from March 10-April 30- 2018.

\section{Study design}

Institution based unmatched case control study design was employed.

\section{Population}

\section{Definition of cases and controls}

Quality of Life was defined by World Health Organization (WHO) short form instrument (WHOQOL-HIV BREF) items. The instrument comprises socio demographics, wealth index, clinical, social support variables, and perceived stigma assessing questions. WHOQOL-HIV BREF contains 31 items distributed into 6 domains: physical, social relationships, level of independence, and spirituality domains each with 4 items and psychological and environmental domains with 5 and 8 items, respectively. The individual items are rated on a 5-point likert scale where 1 indicates low/negative perceptions and 5 indicate high/positive perceptions. The remaining two items measure overall perceived quality of life and general health perception of people living with HIV [30,35-37]. 
Case: Based on the WHOQOL-HIV BREF items, an individual patient living with HIV aged $\geq 15$ years enrolled in to HAART care with poor quality of life was below the mean score of WHOQOL-HIV BREF items.

Control: An individual patient living with HIV and aged $\geq 15$ years enrolled to HAART care with defined good quality of life above the mean score of WHOQOL-HIV BREF) items.

\section{Sample size Determination and sampling technique}

The sample size was calculated by using statistical EPI info 7.1.1 software package by considering the percent of controls exposed of the psychosocial factor (having less social support) among controls is $12 \%$ and among cases $27.1 \%$ with AOR of 2.73 by considering the following parameters: $95 \%$ Confidence Level, $80 \%$ power, a case to control ratio of $1: 3$ accordingly, the final sample size, required was 300(75 cases and 225-controls). Therefore, the largest sample size was taken by considering all objectives which gives more representative sample [31](Table1).

\section{Table1. sample size calculated on predictors of poor quality of life among PLWHIV in Jimma zone public hospitals 2018}

\begin{tabular}{|c|c|c|c|c|c|c|}
\hline Objectives & $\begin{array}{l}\text { Cases to } \\
\text { control } \\
\text { ratio }\end{array}$ & $\begin{array}{l}\% \text { of } \\
\text { controls } \\
\text { exposed }\end{array}$ & OR & $\begin{array}{l}\% \text { of } \\
\text { cases } \\
\text { exposed }\end{array}$ & $\begin{array}{l}\text { Total sample } \\
\text { size }\end{array}$ & $\begin{array}{l}\text { Selected } \\
\text { sample } \\
\text { size }\end{array}$ \\
\hline $\begin{array}{l}\text { Psychosocial(having } \\
\text { less social support) } \\
\text { (34) }\end{array}$ & $1: 3$ & 12 & 2.73 & 27.1 & $\begin{array}{l}300 \text { (75cases \& } \\
225 \text { controls) }\end{array}$ & 1 \\
\hline $\begin{array}{l}\text { Socio economic } \\
\text { factor (Lower } \\
\text { income) } \\
(30)\end{array}$ & $1: 3$ & 34.5 & 2.53 & 54.9 & $\begin{array}{l}220(\text { cases }=55 \\
\& \\
\text { controls }=155)\end{array}$ & 2 \\
\hline $\begin{array}{l}\text { Psycho soci } \\
\text { al factor depression( } \\
\text { 33) }\end{array}$ & $1: 3$ & 7.9 & 3.86 & 24.9 & $\begin{array}{l}207 \text { ( cases }=52 \\
\text { \&controls }=155)\end{array}$ & 3 \\
\hline $\begin{array}{l}\text { Moderate so } \\
\text { cial support } \\
\text { (30) }\end{array}$ & $1: 2$ & 34.8 & 3.3 & 63.8 & $\begin{array}{l}\text { 117(case39\& } \\
\text { controls 78) }\end{array}$ & 4 \\
\hline
\end{tabular}

Simple random sampling technique was employed to select cases and controls. Screening was conducted in order to identify eligible and non-eligible study participants, as a case and controls by the facilitator from each hospital. The screening criteria were taken from WHOQOL Brief tool composed of six components and mean score was considered as a cut of point to classify respondents. Non respondents were replaced by the next cases/controls.

\section{Data collection Instruments and procedures}


Interviewer administered structured questionnaire was used as a data collection tool that was adapted according to local context and objectives of the study[14,20,21]. The questionnaires contain screening part that contain six dimensions of WHO quality of life assessment tool which includes measuring physical dimension, psychological dimension, level of independence, social relations, environmental and religious/spiritual/personal belief which helps identify advanced disease state with recurrent infections.

\section{Data collection procedure}

Face to face interview using short interviewer administered structured questionnaire was employed to identify (to screen) eligible and none eligible participants as well as to classify those eligible clients as cases and controls by facilitators in JUMC and one in the rest hospitals in a private room while waiting for ART services during the study period. After screening of cases and controls, respondents were sent to two data collection rooms then face to face interview was implemented to collect information.

Data collection task was handled by two selected ART nurses in each hospital working in ART clinics. One supervisor was assigned to each site to oversee the process. Data on patients characteristics was collected (Socio-demographic and economic, behavioral and psychosocial data was also interviewed). The principal investigator supervised every aspect of the data collection process along with supervisors and the ART nurses mentored shouldering the regular data collection task. The filled questionnaire was gathered to/by the principal investigator and/or the supervisor on daily basis.

\section{Operational definitions and definition of terms}

For the purpose of this study, i defined quality of life as personal evaluation of how things have been going for one self, and as how the individual's wellbeing may be impacted over time by a disease, a disability, or a disorder.

Good quality of life - an individual patient on ART and whose quality of life measured score above the mean value at $50 \%$ after transformation.

Poor quality of life - an individual patient on ART and whose quality of life measured score is below mean-value at $50 \%$ after transformation.

Stigma: is a perceived negative attribute that cause someone to devalue or think less of the whole person which is measured using mean as a cut of point. Stigmatized those with higher score value above mean and not stigmatized for below mean value[36].

Depression = depression is a mental disorder representing with loss of pleasure or interest, feelings of low self-esteem or guilty, depressed mood, disturbed appetite or sleep, lack of concentration or low energy. Depression was measured using Beck depression inventory (BDI-13score) by PCA considering its internal consistency and reliability with a (Crombach's Alpha 0.935) which is above o.7. It was measured using ordered scale from zero to three where the lower indicates minimal and the higher value indicated severe depression[37]. 
Wealth quintiles: Wealth index is a composite measure of the cumulative living standard of households and was calculated using easy-to collect data on ownership of household assets. Wealth index was generated by using statistical procedure called principal components analysis (PCA) and was categorized in to three quintiles ranked from $1^{\text {st }}$ quintile (poorest), $2^{\text {nd }}$ quintile (middle), $3^{\text {rd }}$ quintile (wealthiest), taken from previously used Ethiopian demographic Health Survey 2016[38].

Satisfaction from the overall support was measured as dissatisfied, somehow satisfied and very satisfied.

Presence of psychosocial support was measured using yes no response for each category.

\section{Data processing and analysis}

Collected data were first checked manually for completeness and consistency by supervisors during the time of data collection and rechecked again at office by the principal investigator before data entry. Then, data was entered into Epi Data version 3.1 and exported to SPSS version 20 for analysis. Quality of life was measured using mean of WHOQOL-HIV BREF items tool [14,20-21,37].

Then, the higher total score denotes higher/good quality of life and the lower score denote low/poor quality of life. Descriptive statistics was done for socio demographic characteristics, behavioral, and psychosocial variables in terms of mean with standard deviations and range values for numerical data as opposed to percentage and frequency tables for categorical data. Principal component analysis for wealth index, stigma and depression score. Cronbach's alpha was used to test for internal consistency and reliability of PCA and accepted above 0.7 and depression score was accepted at scale-reliability of 0.935. Bivariate analysis and multivariate logistic regressions were used and association was declared using AOR at $95 \% \mathrm{Cl}$. The final model was constructed using backward logistic regression method. Model fitness was checked by Hosmer and Lemeshow test statistics and overall classification accuracy test.

\section{Data quality management}

The principal investigator used a pre-tested questionnaire prior to actual data collection and amendments were made. Local language was used to get valid data. Data collectors and supervisors were given training on the data collection tool contents, how to collect data and to make the question items understood uniformly. In the actual data collection process, the principal investigator strictly ensured that the collected data fulfills the expected procedures and kept every question responded properly by the respondent through spot checking. When data collectors face problem during interview, supervisors as well as the principal investigator actively supported them. Data editing, coding and entry was made which then, data cleaning was taken place to check for the consistency of data and identify errors that occur during data collection or coding process.

\section{Ethical Approval and Consent to Participate}


Ethical Clearance was obtained from Jimma University Research Ethics Review Committee.

Formal written letter was obtained from Population and Family health department, to Jimma zone health office and respective hospitals. Permission was obtained from the facilities and written informed consent was obtained from all informants including guardians whose child was under age of 18 years. The interview procedures were conducted completely in a private room. The informants were ensured that all data would be kept confidential by using codes to identify participants and were also clearly informed about their right to refuse to participate in the study or withdraw at any time during the interview session.

\section{Results}

A total of $75(25.0 \%)$ cases and two hundred twenty five (75.0\%) controls were enrolled in the study yielding a response rate of $100 \%$. The mean age of cases was 38.47 (SD \pm 8.93 ) years and $37.79(\mathrm{SD} \pm$ 8.9) for controls, $16(21.3 \%)$ of cases and $140(64.9 \%)$ controls were urban residents beside this $30(40 \%)$ of cases and $81(36 \%)$ controls were male. In addition, $25(33.3 \%)$ of cases $76(33.8 \%)$ of controls were in the lowest wealth quintile (Table 2).

\section{Table 2. Socio demographic and economic characteristics on behavioral and psychosocial determinants of Quality of life among Adult PLWHIV on HARRT, in Public Hospitals of Jimma Zone, South West, Ethiopia 2018}




\begin{tabular}{|lll|}
\hline Variable & $\begin{array}{l}\text { Cases } \\
(\mathrm{N}=75)(\%)\end{array}$ & $\begin{array}{l}\text { Controls } \\
(\mathrm{N}=225)(\%)\end{array}$ \\
\hline Residence & & \\
\hline Urban & $16(21.3)$ & $140(64.9)$ \\
\hline Rural & $59(78.7)$ & $79(35.1)$ \\
\hline Sex & & \\
\hline Male & $30(40)$ & $81(36)$ \\
\hline Female & $45(60)$ & $144(64)$ \\
\hline Age & & \\
\hline$<=24$ & $2(2.7)$ & $7(3.1)$ \\
\hline 25-34 & $18(24)$ & $77(34.2)$ \\
\hline 35-44 & $38(50.7)$ & $94(41.8)$ \\
\hline$>=45$ & $17(22.7)$ & $47(20.9)$ \\
\hline Employment & & \\
\hline Employed & $51(68)$ & $119(52.9)$ \\
\hline Unemployed & $24(32)$ & $106(47.1)$ \\
\hline Educational status & & \\
\hline <=grade 4 & $36(48)$ & $70(31.1)$ \\
\hline Primary(5-8) & $18(24)$ & $79(35.1)$ \\
\hline Secondary(8-12) & $11(14.7)$ & $43(19.1)$ \\
\hline Post Secondary & $10(13.3)$ & $33(14.7)$ \\
\hline Religion & & \\
\hline Orthodox & & \\
\hline Muslim & & \\
\hline Protestant, Catholic & $3(4.0)$ & $14(4.9)$ \\
\hline Ethnicity & & \\
\hline
\end{tabular}




\begin{tabular}{|lll|}
\hline Other & $12(9.3)$ & $11(4.9)$ \\
\hline Marital status & & \\
\hline Single & $6(8)$ & $20(8.9)$ \\
\hline Separated, divorced & $18(24)$ & $31(13.8)$ \\
\hline Wealth status & & \\
\hline $1^{\text {st }}$ quintile & $25(33.3)$ & $76(33.8)$ \\
\hline $2^{\text {nd }}$ quintile & $24(32)$ & $76(33.8)$ \\
\hline $3^{\text {rd }}$ quintile & $26(34.7)$ & $73(32.4)$ \\
\hline BMl & & \\
\hline Under weight & $23(31.1)$ & $43(19.1)$ \\
\hline Normal & $35(47.3)$ & $133(59.1)$ \\
\hline Over/obese & $16(21.6)$ & $49(21.8)$ \\
\hline
\end{tabular}

Regarding characteristics of behavioral factors, 33(44\%) of cases and 107(46.4\%) controls have experienced any kind of substances ever. HIV/AIDS status disclosure was almost similar in both cases and controls with about $76 \%$ and $75.6 \%$ respectively(Table3).

Table3. Characteristics of behavioral factors with poor quality of life among PLHIV in Jimma zone public hospitals, South west Ethiopia 2018 


\begin{tabular}{|c|c|c|}
\hline Variable & $\begin{array}{l}\text { Cases } \\
(\mathrm{N}=75)(\%)\end{array}$ & $\begin{array}{l}\text { Controls } \\
(\mathrm{N}=225)(\%)\end{array}$ \\
\hline \multicolumn{3}{|c|}{ Ever use of any substance } \\
\hline Yes & $33(44)$ & $107(46.4)$ \\
\hline No & $42(56)$ & $118(53.6)$ \\
\hline \multicolumn{3}{|l|}{ Ever use of alcohol } \\
\hline Yes & $17(22.7)$ & $41(18.8)$ \\
\hline No & $58(77.3)$ & 184(81.2) \\
\hline \multicolumn{3}{|l|}{ Ever use of khat } \\
\hline Yes & $23(30.7)$ & 76(33.8) \\
\hline No & $52(69.3)$ & $149(66.2)$ \\
\hline \multicolumn{3}{|l|}{ Ever use of tobacco } \\
\hline Yes & 13(17.3) & $46(20.4)$ \\
\hline No & $62(82.7)$ & 179(79.6) \\
\hline \multicolumn{3}{|l|}{ Alcohol frequency } \\
\hline Never & $60(80)$ & $208(92.4))$ \\
\hline Once-4 times/month & 13(17.3 & 16(7.1) \\
\hline daily & $2(2.7)$ & $1(1.4)$ \\
\hline \multicolumn{3}{|l|}{ Chat frequency } \\
\hline Never & $53(70.7)$ & $176(78.2)$ \\
\hline Once-4 times/month & 14(18.7) & $37(16.4)$ \\
\hline 7 times/Week/Daily & $8(10.7)$ & $12(5.3)$ \\
\hline \multicolumn{3}{|l|}{ Tobacco frequency } \\
\hline Never & 68(90.7) & 208(92.4) \\
\hline Once-4 times/month & $4(5.3)$ & $12(5.3)$ \\
\hline 7 times/Week/Daily & $3(4)$ & $5(2.2)$ \\
\hline \multicolumn{3}{|l|}{ HIV Disclosure } \\
\hline Yes & $57(76)$ & $170(75.6)$ \\
\hline No & $18(24)$ & $55(24.4)$ \\
\hline
\end{tabular}


Regarding characteristics of psychosocial factors, 37(49.3\%) of cases and 139(61.8\%) have obtained support of different kind. 58(77.3) of cases, 193(85.8) controls were satisfied/very satisfied with the overall support whereas, 41 (54.7) of cases and 31(13.8) of controls were stigmatized along with 38(50.7) of cases and 42(18.7) of controls were severely depressed(Table 4).

Table 4 Characteristics of psychosocial factors on poor quality of life among PLHIV in Jimma zone public hospitals, South west Ethiopia 2018 


\begin{tabular}{|c|c|c|}
\hline Variable & $\begin{array}{l}\text { Cases } \\
(\mathrm{N}=75)(\%)\end{array}$ & $\begin{array}{l}\text { Controls } \\
(\mathrm{N}=225)(\%)\end{array}$ \\
\hline \multicolumn{3}{|c|}{ Getting support } \\
\hline Yes & $37(49.3)$ & $139(61.8)$ \\
\hline No & $38(50.7)$ & $86(38.2)$ \\
\hline \multicolumn{3}{|c|}{ Getting Emotional support } \\
\hline Yes & 13(17.3) & $63(28)$ \\
\hline No & $62(82.7)$ & $162(72)$ \\
\hline \multicolumn{3}{|c|}{ Getting financial support } \\
\hline Yes & 14(18.7) & $44(19.8)$ \\
\hline No & $61(81.3)$ & $181(80.4)$ \\
\hline \multicolumn{3}{|c|}{ Getting Physical Care and Support } \\
\hline Yes & $15(20)$ & $62(27.6)$ \\
\hline No & $60(80)$ & $163(72.4)$ \\
\hline \multicolumn{3}{|c|}{ Support obtained from friends } \\
\hline Yes & $2(2.7)$ & 16(7.10 \\
\hline No & 73(97.3) & 209(92.9) \\
\hline \multicolumn{3}{|c|}{ Non-Government Organization } \\
\hline Yes & $6(8)$ & $8(3.6)$ \\
\hline No & $69(92)$ & $217(96.4)$ \\
\hline \multicolumn{3}{|c|}{ Community Based Organization } \\
\hline Yes & $1(1.3)$ & $7(3.1)$ \\
\hline No & 74(98.7) & 218(96.9) \\
\hline \multicolumn{3}{|c|}{ Religious Based Organization } \\
\hline Yes & $0(0.00)$ & $7(3.1)$ \\
\hline No & $75(100)$ & 218(96.9) \\
\hline \multicolumn{3}{|c|}{ Government Organization } \\
\hline Yes & 14(18.7) & $34(15.1)$ \\
\hline No & 61(81.3) & 191(84.9) \\
\hline
\end{tabular}




\begin{tabular}{|lcl|}
\hline From Work Place & & \\
\hline No & $2(2.7)$ & $1(0.4)$ \\
\hline From Family & $73(97.3)$ & $224(99.6)$ \\
\hline Yes & & \\
\hline No & $18(24)$ & $100(44.4)$ \\
\hline Satisfaction of the overall support & \\
\hline Dissatisfied & $57(76)$ & $125(55.6)$ \\
\hline Somehow & $11(14.7)$ & $3(1.3)$ \\
\hline Dissatisfied & $6(8.0)$ & $29(12.9)$ \\
\hline Very satisfied & & \\
\hline Neither dissatisfied/satisfied & $37(49.3)$ & $92(40.9)$ \\
\hline Stigma & & \\
\hline Stigmatized & $21(28.0)$ & $101(44.9)$ \\
\hline Not stigmatized & $41(54.7)$ & $31(13.8)$ \\
\hline Depression & $34(45.3)$ & $194(86.2)$ \\
\hline Minimal & & \\
\hline Mild & $15(20)$ & $95(42.2)$ \\
\hline Moderate & $3(10.7)$ & $37(16.4)$ \\
\hline Severe & $14(18.7)$ & $51(22.7)$ \\
\hline
\end{tabular}

\section{Determinant Factors Associated with poor quality of life}

Based on the assumption of P-value $<0.25$ in the bivariate logistic regression analysis indicated that residence, religion, ethnicity, employment status, BMI, Alcohol frequency, khat chewing frequency, Getting support, Getting Emotional support, Getting physical care and support, , support from NGO, From Work Place, support from family, Satisfaction of the overall support, Stigma and depression were selected candidate variables.

The odds of poor quality of life among the socioeconomic factors being underweight $\left(\mathrm{BMI} \mathrm{kg} / \mathrm{m}^{2}\right.$ ) were about 2.7 times more likely as compared to their counter parts AOR $2.795 \% \mathrm{Cl}(1.0,7.1)$, similarly the odds of poor quality of life among those who khat chewing frequently 1-4 times/weak/month were about 4.5 times AOR $4.595 \% \mathrm{Cl}(1.85,10.9)$ and at daily intervals 4.7 times more AOR $4.795 \% \mathrm{Cl}(1.18,18.8)$ likely than who never chew respectively. Regarding psychosocial factors, being dissatisfied from over all 
support were nearly ten times at AOR $9.895 \% \mathrm{Cl}(1.9,50)$ than satisfied/very satisfied respondents. The odds of poor quality of life among stigmatized patients were 8 times more likely than non-stigmatized at AOR $8.095 \% \mathrm{Cl}(3.6,18.1)$. Moreover, the odds of poor quality of life among severely depressed patients were 4 times AOR $4.095 \% \mathrm{Cl}(1.67,9.83)$ more likely than mild depressed patients (Table 5).

\section{Table 5. Multivariate logistic regression analysis on behavioral and psychosocial} factors with poor quality of life among PLHIV in Jimma zone public hospitals, South west Ethiopia 2018 


\begin{tabular}{|c|c|c|c|c|}
\hline Variable & $\begin{array}{l}\text { Cases } \\
(\mathrm{N}=75)(\%)\end{array}$ & $\begin{array}{l}\text { Controls } \\
(\mathrm{N}=225)(\%)\end{array}$ & $\operatorname{COR}(95 \% \mathrm{Cl})$ & AOR(95\% Cl) \\
\hline \multicolumn{5}{|l|}{ BMI cat } \\
\hline Under weight & $23(31.1)$ & $43(19.1)$ & $0.6(0.73,3.49)$ & $2.7(1.0,7.1) *$ \\
\hline Normal & $35(47.3)$ & $133(59.1)$ & $0.8(0.41,1.58)$ & $0.94(0.4,2.3)$ \\
\hline Over/obese & $16(21.6)$ & $49(21.8)$ & - & 1.00 \\
\hline \multicolumn{5}{|l|}{ Khat chewing frequency } \\
\hline Never & $53(70.7)$ & $176(78.2)$ & - & 1.00 \\
\hline 1-4 times perweak/ month & 14(18.7) & $37(16.4)$ & $1.25(0.65,2.5)$ & $4.5(1.85,10.9) *$ \\
\hline Daily & $8(10.7)$ & $12(5.3)$ & $2.21(0.86,5.7)$ & $4.7(1.18,18.8) *$ \\
\hline \multicolumn{5}{|c|}{ Satisfaction from support obtained } \\
\hline Dissatisfied & 11(14.7) & $3(1.3)$ & $9.1(2.4,34.6)$ & $9.8(1.9,50.0) *$ \\
\hline Somehow & $6(8.0)$ & $29(12.9)$ & $0.51(0.19,1.34)$ & $1(0.0,9.8)$ \\
\hline \multicolumn{5}{|l|}{ Dissatisfied } \\
\hline Very satisfied & $21(28.0)$ & $101(44.9)$ & $0.51(0.28,0.85)$ & $1(0.5,0.6)$ \\
\hline Neither dissatisfied/satisfied & $37(49.3)$ & $92(40.9)$ & - & 1.00 \\
\hline \multicolumn{5}{|l|}{ Stigma } \\
\hline Stigmatized & $41(54.7)$ & $31(13.8)$ & $7.5(4.2,13.6)$ & $8 \cdot 0(3.6,18.1) *$ \\
\hline Not stigmatized & $34(45.3)$ & 194(86.2) & - & 1.00 \\
\hline \multicolumn{5}{|l|}{ Depression } \\
\hline Minimal & $15(20)$ & $95(42.2)$ & - & 1.00 \\
\hline Mild & $8(10.7)$ & $37(16.4)$ & $1.4(0.53,3.5)$ & $1.6(.54,0.80)$ \\
\hline Moderate & 14(18.7) & $51(22.7)$ & $1.3(0.78,3.89)$ & $1.0(0.40,0.96)$ \\
\hline Severe & $38(50.7)$ & $42(18.7)$ & $5.7(2.8,11.5)$ & $4.0(1.67,9.83)^{*}$ \\
\hline
\end{tabular}

\section{Discussion}

This study has identified independent overall factors which includes, Nutritional status $\left(\mathrm{BMI} \mathrm{kg} / \mathrm{m}^{2}\right)$, frequency of chat chewing, stigma, depression, lack of satisfaction from support. Most of the identified overall factors in the current study are most strongly associated with the outcome variable. The most highly significantly associated overall factors with poor quality of life are those who were underweight 
$\left(\mathrm{BMI} \mathrm{kg} / \mathrm{m}^{2}\right)$, chew khat 1-4 times/weak/month, and at daily intervals and severely depressed. Similarly being dissatisfied from overall support obtained stigmatized patients were also independently associated with poor quality of life.

Among the socio demographic and economic factors, the likelihood of poor quality of life among underweight participants $\left(\mathrm{BMl}<18.5 \mathrm{~kg} / \mathrm{m}^{2}\right)$ was about 2.7 times higher than their counter respondents. $A$ study provokes nutritional supplementation improved quality of life[39]with comparable cohort of Irish thought that the likelihood of having lower Health Related Quality of Life in individuals with abnormal $\mathrm{BMI}$ categories of WHO classification especially among underweight and overweight respondents than the normal one[40]. Food insecurity has been associated with poor quality [41]with lack of access to different kind of food which causes to be under weight and that in turn exposes patients to the treatment non adherence [40]. Likewise, the other study from George $S$ et al and Pederson KK showed that three parameters (height, weight, and BMI) were found to be significantly associated[40,43].

With regard to the behavioral factors, the odds of poor quality of life among participants who chew khat 1-4 times/weak/month were about 4.5 times and at daily intervals 4.7 times more likely than who never chew respectively. This was supported with the study done in Northern Ethiopia that substance uses among patients during ART medication was also found to be the independent determinant factors of nonadherence [40].

Regarding psychosocial factors, the odds of poor quality of life among respondents dissatisfied from the support obtained were about 9.8 times more likely than participants who satisfied and very satisfied from the overall support obtained. Studies have also shown that lack of obtaining social support made leads to poor QOL[24,29]. Study from Bejing identified that family support along with no or minimal discrimination was found to contribute to QOL among people infected with HIV[45]. The odds of poor quality of life among stigmatized respondents were about 8 times more likely than none stigmatized. This study is supported by the finding conducted in Mekele town Northern Ethiopia, Southern India and report of united Kingdom showed that high perceived stigma, severe self-stigma and those with severe disclosure concerns were strongly associated with poor quality of life $[17,21-2,26]$. Stigma is a big concern where by forty-eight percent of women and $35 \%$ of men thought that children living with HIV should not be able to attend school with children who are HIV negative; $55 \%$ of women and $47 \%$ of men would not buy fresh vegetables from a shopkeeper with HIV[38,40].

The other point identified that the odds of poor quality of life among severely depressed PLWHIV were about 4 times more likely than participants with mild depression. This is consistent with studies done in a similar setting by (Legese Mekuria), Alemayehu Wubshet and Pederson KK that the higher levels of depressive-symptoms were most strongly associated with a lower HRQoL, followed by high levels of HIVstigma[17,29, 43, 45]. 


\section{Limitations of the study}

There was a possibility that social desirability influenced patients' answer which might over/under report some of the behavioral, there was a possibility of misclassifying cases and controls and using relatively a strong design. Despite these limitations, the study has strengths. Training of data collectors helped to reduce social desirability bias, identification of eligible and non-eligible participants were also performed by controlling possible confounders.

\section{Conclusion}

In conclusion, the present study identified some of the factors that facilitate poor quality of life, which may inform possible interventions for increasing the level of quality of life among PLWHIV, thus helping to reduce comorbidities and disease exacerbation by improving monitoring and evaluation of patients' outcomes. Most of the identified overall factors in the current study are most strongly associated with the outcome variable. The most highly significantly associated overall factors with poor quality of life are those who were underweight $\left(\mathrm{BMI} \mathrm{kg} / \mathrm{m}^{2}\right)$, chew khat 1-4 times/weak/month, and at daily intervals and severely depressed. Similarly being dissatisfied from overall support obtained stigmatized patients were also independently associated with poor quality of life.

In ordered to curb consequences of poor quality of life among respondents in the study area, it will become all the most important to develop effective interventions to assist PLWHIV to safely live and enjoy healthy life. Therefore, health professionals should advice on the uptake of nutritionally valued and modified dietary practice. Programs should be delivered to PLWHIV to develop life skills that would help them cope-up with adverse behavioral factors like chewing khat. Along with this, psychosocial support should be provided from different perspectives and sources. Counseling should also be adhered to halt the consequences of depression and stigma.

\section{Abbreviations}

AGH: Agaro General Hospital, AIDS: Acquired Immune Syndrome, ART: Antiretroviral Therapy, BFS: Baseline Functional Status,CD4: Cell Cluster of differentiation4: BMI Body Mass Index, HAART: Highly Active Antiretroviral Therapy, HIV: Human Immunodeficiency Virus, Ols: Opportunistic Infections, PCA: Principal Component Analysis, PI: Principal Investigator, PLWHIV: People Living With HIV,QOL: Quality of Life, SGGH: Shenen Gibe General Hospital, WHO: World Health Organization, WHOQOL: World Health Organization Quality Of Life.

\section{Declarations}

\section{Consent for publication}

Not applicable 
Availability of data and materials

The data sets used and/or analyzed during the current study are available from the corresponding author of the research on reasonable request.

\section{Competing interests}

The authors declare that they do not have competing interest.

\section{Funding:}

This study was funded by Jimma University, Institute Health. The views presented in the article are of the author and not necessarily express the views of the funding organization.

\section{Author contributions}

AA: Involved in the inception, design, data acquisition, analysis and interpretation, and wrote the manuscript. YG and EZ: Participated in data acquisition, analysis and involved in critical reviewing of the manuscript. Finally, all Authors read and approved the manuscript.

\section{Acknowledgements:}

Study participants are greatly acknowledged for the information they provided. Jimmma University is highly acknowledged for covering the cost of the study.

\section{References}

1. . The Henry J. Kaiser Family Foundation Headquarters (Washington DC):Filling the need for trusted information on national health issues; The Global HIV / AIDS Epidemic. Fact sheet. 2017.

2. The Joint United Nations Programme on HIV and AIDS(UNAIDS);Regional HIV Statistics. Fact sheet [Internet]. 2017;(July):1-8. Available from: Communications and Global Advocacy \%7C +41 22791 1697 \%7C communications @unaids.org. Additional data are available at :aidsinfo.unaids.org\%0A8.

3. Ethiopia Country / Regional Operational Plan ( COP / ROP ) 2017 Strategic Direction Summary. 2017

4. Democratic F. Federal Democratic Republic of Ethiopia | Ministry of Health;National Guidelines for Comprehensive HIV Prevention, Care and Treatment, 2014. 2014;

5. World Health Organization (WHO): Guidelines for managing advanced HIV disease and rapid initiation of antiretroviral therapy, July 2017. Geneva: World Health Organization; 2017. Geneva: WHO;

6. World HealthOrganization(WHO): Global health sector response to HIV, 2000-2015. 2015.

7. Press D. Quality of life of people living with HIV and AIDS and antiretroviral therapy. 2012;117-24.

8. World HealthOrganization(WHO): Progress Report on Prevent HIV, Test And Treat All; WHO Support For Country Impat Geneva 27, Switzerland. 2016; Available from: World Health Organization, 20 
Avenue Appia, 1211 Geneva 27, Switzerland

9. Oguntibeju OO. Quality of life of people living with HIV and AIDS and antiretroviral therapy. HIV AIDS (Auckl) [Internet]. 2012;4:117-24. Available from:

http://www.pubmedcentral.nih.gov/articlerender.fcgi?artid=3418767\&tool=pmcentrez\&rendert

10. Ns et al, Long-term HIV infection and health-related quality of life. s.I. : news bulletin, 21. 2014; (October).

11. U.S. Department Of Health AND Human Services Centers for Disease Control and PreventionServices H. Population Assessment of Health-Related Quality of Life. 2000.

12. An Application of Methods for Monitoring the Results of Medical. The Medical Outcomes Study Journal JT: September 1989

13. Higginson IJ, Carr AJ. Using quality of life measures in the clinical setting. :1297-300.

14. The WHOQOL Group, Programme on Mental Health, WHO, CH-1211 Geneva 27, Switzerland. 1996; (December).

15. TAM V VAN. Enhanced Antiretroviral Treatment support in relation to Quality of Life and Virological failure in low-income setting: a cluster randomized controlled trial in Quang Ninh, Vietnam. 2013; (Karolinska Stockholm, Sweden).

16. Khamarko K, Myers JJ. The Influence of Social Support on the Lives of HIV-Infected Individuals in Low- and Middle-Income Countries. 2013;1-40.

17. Legese A Mekuria, Jan M Prins, Alemayehu W Yalew, Mirjam AG Sprangers PTNAC 2015; Health related quality of life of HIV-infected adults receiving combination antiretroviral therapy in Addis Ababa. 2015;27(8):934-45.

18. Since V, Ilo T. Global T, Pact J, Pact T, Recommendation ILO, States M, Hiv I, et al. Global Jobs Pact Policy: Income generation and sustainable livelihoods for people living with and affected by HIV and AIDS. Brief No-1(December):1-4.

19. The Joint United Nations Programme on HIV/AIDS (UNAIDS):UNAIDS Data 2017;20 Avenue Appia 1211 Geneva 27 Switzerland. 2017:Available from: unaids.org

20. Amare Alemu, AY, , Feleke A, Meseret and S ; Health Related Quality of Life Assessment and Associated Factors Among People on Highly Active Antiretroviral Therapy at Felege Hiwot Referral Hospital, BahirDar,North West Ethiopia. 2013;5(1):1-5.

21. Tesfay A, Gebremariam A, Gerbaba M, Abrha H. Gender Differences in Health Related Quality of Life among People Living with HIV on Highly Active Antiretroviral Therapy in Mekelle Town, Northern Ethiopia. 2015;2015.Jadhav PS, Laad PS, Chaturvedi RM. Quality of life factors affecting quality of life in people living with HIV / AIDS in an urban area. 2017;4(8):3031-6.

22. Lakew Y, Benedict S, Haile D. Social determinants of HIV infection, hotspot areas and subpopulation groups in Ethiopia: evidence from the National Demographic and Health Survey in 2011, 2015. 
23. Mbada CE, Onayemi O, Ogunmoyole Y, Johnson OE, Akosile CO. Health-related quality of life and physical functioning in people living with HIV / AIDS: a case - control design. Health Qual Life Outcomes [Internet]. 2013;11(1):1. Available from: Health and Quality of Life Outcomes

24. Surur AS, Teni FS, Wale W, Ayalew Y, Tesfaye B. Health related quality of life of HIV / AIDS patients on highly active anti-retroviral therapy at a university referral hospital in Ethiopia. 2017;1-8.

25. Soboka M, Tesfaye M, Feyissa GT, Hanlon C. Alcohol use disorders and associated factors among people living with HIV who are attending services in south west Ethiopia. 2014;1-9.

26. Egbe CO, Dakum PS, Ekong E, Kohrt BA, Minto JG, Ticao CJ. Depression, suicidality , and alcohol use disorder among people living with HIV / AIDS in Nigeria. 2013;1-13.

27. Gebrezgabher BB, Kebede Y, Kindie M, Tetemke D, Abay M. Determinants to antiretroviral treatment non - adherence among adult HIV / AIDS patients in northern Ethiopia. AIDS Res Ther. 2017;1-7.

28. Endeshaw MM. Stigma: A Contributing Factor to Depressive Symptoms in People with HIV Seeking Treatment at Gondar University Hospital. J Artic. 2012;

29. Charles B, Jeyaseelan L, Pandian AK, Sam AE, Thenmozhi M. Association between stigma, depression and quality of life of people living with HIV / AIDS ( PLHA) in South India - a community based cross sectional study. BMC Public Health [Internet]. 2012;12(1):1 Available from: BMC Public Health

30. Mu E. Does duration on antiretroviral therapy determine health-related quality of life in people living with HIV? A cross-sectional study in a regional referral hospital in Kenya. 2014;9716(January 2018).

31. Folasire OF, Folasire AM, Sanusi RA. Measures of Nutritional Status and Quality of Life in Adult People Living with HIV / AIDS at a Tertiary Hospital in Nigeria. 2015;(March):412-20.

32. Khamarko K, Myers JJ. The Influence of Social Support on the Lives of HIV-Infected Individuals in Low- and Middle-Income Countries. 2013;1-40.

33. S T, et.al. Assessing Quality Of Life and Depression Among People Living With HIV / AIDS and TBHIV Coinfection In Kathmandu,Nepal. SAARC J Tuberc Lung Dis HIV/AIDS. 2014.

34. Imam M, Karim M, Ferdous $C$, and Akhter S. "Health related quality of life among the people living with HIV. Bangladesh Medical Research Council Bulletin, 2011, 37(1),1-6.

35. Utel K, Pisarev H, Loit H, and Uuskula A. "Factorsinfluencing quality of life of people living with HIV in Estonia. Health Qual Life Outcomes 2016,14(3);1-12.

36. (NEP+): $\mathrm{N}$ of $\mathrm{N}$ of HP in E. Summary of Findings Report in Ethiopia; [Internet]. Summary of Findings Report in Ethiopia; Arada sub city; 2011. Available from: website: www.nepplus.org

/Email: aelwha@ethionet.et

37. Farinde A. The Beck Depression Inventory. 2013;56-62. Available from: www.thepharmajournal.com/ [E-mail:aofpharm420@hotmail.com]

38. Federal Democratic Republic of Ethiopia(FDRE):Central stastics Ageny. Key Indicator Report. Ethiopian Demographic Health Survey(EDHS). Addis Ababa, Ethiopia; 2016. 
39. M. Tesfaye et al. the effect of nutritional supplementation on quality of life in people living with HIV: a randomised controlled trial; Tropical Medicine and International Health june 2016: volume 21 no 6 pp 735-742

40. George S, Bergin C, Clarke S, Courtney G, Codd MB. Health-related quality of life and associated factors in people with HIV: an Irish cohort study. Health Qual Life Outcomes [Internet]. 2016;1-12. Available from: http://dx.doi.org/10.1186/s12955-016-0517-4

41. Tesfaye et al. Food insecurity, mental health and quality of life among people living with HIV commencing antiretroviral treatment in Ethiopia: a cross-sectional study Health and Quality of Life Outcomes (2016) 14:37.

42. Gebrezgabher et al. Determinants to antiretroviral treatment non-adherence among adult HIV/AIDS patients in northern Ethiopia. AIDS Res Therapy (2017), 14:16

43. Pedersen KK, Eiersted MR, Gaardbo JC, Pedersen M, Gerstoft J, Troseid M, et al. Lower Self-Reported Quality of Life in HIV-Infected Patients on CART and With Low Comorbidity Compared With Healthy Controls. 2015;70(1):16-22.

44. Alemayehu M, Wubshet M, Mesfin N, Tamiru A, Gebayehu A. Health-related quality of life of HIV infected adults with and without Visceral Leishmaniasis in Northwest Ethiopia. 2017;1-10

45. Xu et al. Infectious Diseases of Poverty Family support, discrimination, and quality of life among ARTtreated HIV-infected patients: a two-year study in China (2017) 6:152: DOI 10.1186/s40249-017-0364-5. 